\title{
A Framework to Establish Passengers' Satisfactory Key Indicators and Index in Speed Boat Ferry Service Operations
}

\author{
Garrick Pereowei Ombor ${ }^{1, a^{*}}$, Elizabeth Oshuare Ombor ${ }^{2, b}$, Sidum Adumene \\ ${ }^{1}$ Marine Engineering Department, Federal University of Petroleum Resources, Nigeria \\ ${ }^{2}$ The Marine Chaplains Foundation, Nigeria \\ ${ }^{3}$ Marine Engineering Department, Rivers State University of Science and Technology, Nigeria \\ aombor.pereowei@fupre.edu.ng, bomborliz77@@gmail.com, c'sidum.adumene@ust.edu.ng
}

Keywords: Delphi technique, Likert scale, AHP Analysis, Speed boat, Ferry, passengers' satisfactory key indicators and index, dominant factors, Kendall's coefficient of concordance, fuzzy set definitions

\begin{abstract}
This study provides a framework to holistically assess the level of passengers' satisfaction for a given ferry service based on the dominant Design/Operational, Passengers Care/Safety/Security and Environmental categorical factors that define the ferry service operations and influence passengers' satisfaction. A test case carried out for a ferry service offered by a boat operator in the Warri wharf yields a Passengers' Satisfaction Index of 3.84, indicating that the ferry service is in the range of dissatisfactory and moderately satisfactory, which is in good agreement with popular opinions that the service offered by that operator does not satisfy most of the passengers' expectations. The results of the test case proved that the framework reliably and realistically predicts the level of satisfaction the passengers derived from the various segments that define the service offered by a boat operator. This study will assist passengers make informed decision about the choice of operators to patronize. It will also guide operators and regulators to identify and improve those areas of the ferry service that are pertinent to the successful operation of the ferry business.
\end{abstract}

\subsection{Introduction}

There are many islands existing today, especially in developing countries that can only be accessed by boats. Passengers in such islands are usually subjected to whatever conditions imposed on them by the boat operators. In situations where the ferry service regulators are passive, passengers complain that there is no alternative transport mode to and from their destination. However, the level of passengers' satisfaction is highly subjective, as there are several factors influencing the opinions of the passengers. As such, each passenger measures the satisfaction derived from the ferry service differently. Situations like this presents an opportunity to establish key indicators and index of passengers' satisfaction in order to have a consensus idea about how satisfied passengers are for a given service offered by a boat operator.

\subsection{Research questions}

The establishment of such Passengers' Satisfactory Key Indicator (PSKI) and Passengers' Satisfactory Index (PSI) requires the development of a framework that will provide answers to the following research questions:

1. What are the factors that influence passengers' satisfaction?

2. How can the dominant factors influencing passengers' satisfaction be determined and categorized?

3. How much do these categories of dominant factors influence passengers' satisfaction? 
A brief consideration reveals that the first two questions are qualitative and highly subjective. Hence, questions 1 and 2 should be addressed subjectively to identify the pertinent factors. The factors that influence passengers' satisfaction can be derived using a traditional statistical sampling technique where the researcher randomly selects a sample that represents the population of interest. While this method appears to be suitable at a first glance, the reliability and confidence on the consensus factors (which is basically an average of the responses for the sample generalized to the relevant population) is questionable. Chances are that the representative population (which may not actually be represented as a result of non-response) might not be knowledgeable enough about the industry to answer the questions accurately.

Moreover, the mode of choices made by a crowd tend to be better than the choice of an average person and that the consensus decision reached by a crowd tend to exhibit the signs of expertise [1]. A group of experts and experienced persons in a particular domain will provide a more accurate result than a modal consensus output from a crowd source.

The categorization of the various factors that influence passengers' satisfaction as noted earlier is subjective. However, a consensus answer to the questions should provide a solid pathway to establish PSKI and PSI for the ferry service. The application of categorical judgement to articulate systems and process information has been reported to be quite common, convenient and positive[2]. Researchers have shown that the naming of a category is an abstraction activity involving analytical reasoning while the name given to a category do not really matter $[3,4,5]$. The act of naming a category reflects a good knowledge of the right attributes of the factors that is shared with the group's or category's unique features. In other words, the peculiar features of a category are exhibited or possessed by the factors belonging to that category.

The ability to see the connection between a factor and a group with certain peculiar characteristics is crucial for the categorization of the factor into that group. The concepts of conceptual proximity[6] and structural similarities[7] can be used to group into categories factors that share certain similar characteristics related to passengers' satisfaction. The abstraction of similar characteristics from the list of factors influencing passengers' satisfaction require the use of experts with strong analogical reasoning. Though analogy can be used to solve many problems[8], analogical reasoning is difficult because so much must be mastered[1]. To use analogical reasoning, the problem and solution domain must be well understood, the user must know how to abstract both relevant features and unimportant surface details and match related features[9,10]. It must be emphasized that analogies are rarely perfect, the user of analogy must decide which aspects are critical.

From the list of factors influencing the level of passengers' satisfaction, it is almost certain that several categories can be generated by different persons. In general, the set of factors are grouped into a small number of categories with varying labels. In certain situations, the list of factors or objects can have more than one level of categorization. In other words, the list of factors may first be split into two or more categories and one or more categories may be further sub-divided into subcategories (a second level of category). Moreover, some factors may belong to multiple categories. It has been shown that uncertainties, errors and complex categories (including categories with shared factors) arising from the use of analogical reasoning for categorization by individuals can be smoothened out by using the high quality forced-directed consensus graphics method[11,12,13]. The third question which is objective can be addressed when the identified factors are subjected to quantitative assessment to verify their pertinence and significance on the level of passengers' satisfaction. Appropriate methods exist that can be used to determine the rank and importance weight of dominant factors in any category. The Likert point scale is an established tool that have been used to aggregate expert opinions in deciding the importance of as well as screen items or factors from a list. The Likert 5-point scale is shown in Fig.1 below: 


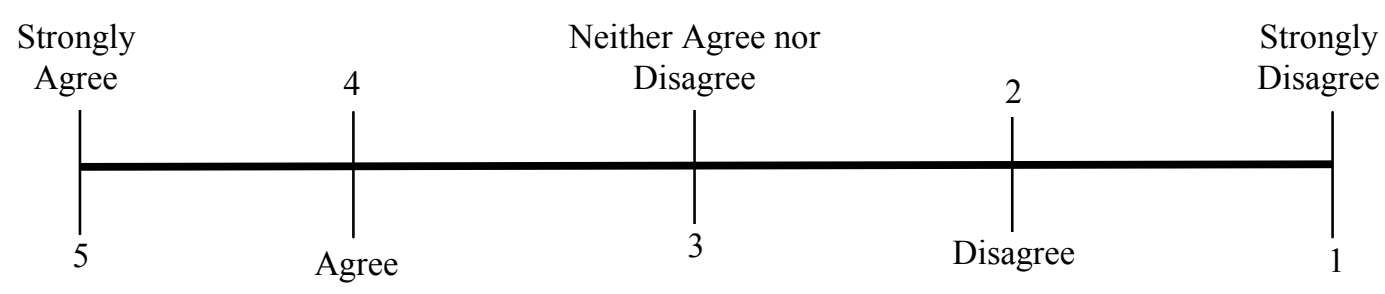

Fig.1: Likert 5-Point Scale

In the application of the Likert 5-point scale, each expert chooses a linguistic variable (Strongly Agree, Agree, Neither Agree nor Disagree, Disagree and Strongly Disagree) to state his or her opinion about a given factor, statement, rating or fact. Where there is consensus among the participating experts, factors whose mean linguistic value (1 to 5) from the pool of expert opinions are lower than four in the Likert Scale are regarded as out of consensus.

Kendall's coefficient of concordance provides a very reliable method to determine factors that mostly influence the outcome of a system or process. The value of the sum of the ranks assigned by all the experts to a given $i$ th factor expressed as $\mathrm{R} i$, gives an idea about the level of importance (rank) of that factor in a list of factors if there is consensus of experts' opinion. The factor with the smallest $\mathrm{Ri}$ value is taken as the most important and ranked first. The Kendall's Coefficient of Concordance $\mathrm{W}$ which indicates the level of consensus about an opinion ranges between 0 and 1 . Values of W near 0 implies strong disagreement and values closer to 1 means strong agreement.

\subsection{Fuzzy linguistic variables}

These are variables that are assigned statements as their values. They are very important in qualitative analysis where judgements or opinions are subjective and imprecise. In the assessment of passengers' satisfactory level for ferry service offered by operators, linguistic variables are generally used by passengers to express their opinion about certain factors influencing the nature of service rendered as well as the level of the passengers' satisfaction.

Tables 4, 5 and 6 show the linguistic variables, their values and the criteria used to rate the passengers' opinion (POV) about the dominant factors influencing passengers' satisfaction while Table 7 shows the linguistic variables, their values and the criteria used to describe Passengers' Satisfaction (PS). The fuzzy PS set definition derived from the study participants' consensus opinions is shown in Fig.3.

\subsection{Framework for Developing Passengers Satisfaction Index (PSI)}

Various methods to elicit and process expert opinions has been introduced. The proposed framework to establish the PSI and category based PSKI is shown in Fig.2.

The framework is developed by constituting four panels of experts/stakeholders that develop and make use of three categories of factors to articulate passengers' satisfactory sentiments and information. The framework capitalizes on a rigorous methodology to query, elicit and extract experts' and stakeholders' judgement about the level of passengers' satisfaction under varying conditions of ferry service. 


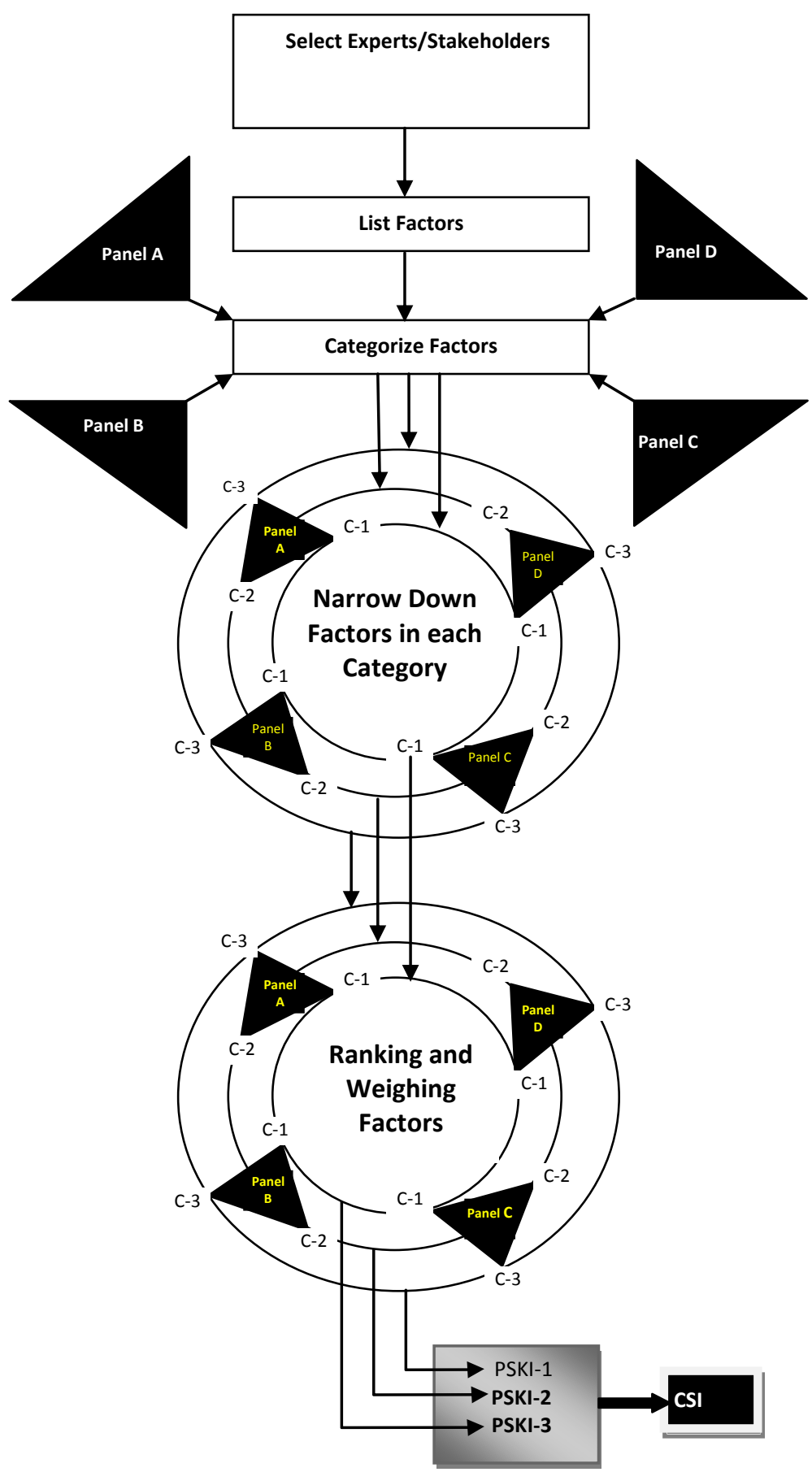

Fig.2:PSI and PSKI Development Framework

The Delphi technique has been well recognized as a reliable research method for establishing, structuring and controlling the interaction and communication process of a group of individuals, experts and stakeholders to obtain the most reliable consensus opinion or judgement by using a series of robust questionnaires combined with controlled feedback for data collection, assessment and evaluation to deal with a complex and often subjective problems. However, the success in the use of Delphi method is dependent on the theoretical framework used to conduct the research and the statistical tools used to support the conclusions drawn[14,15].

In this study, a rigorous importance ranking and rating type Delphi method will be used to develop group consensus about the relevance and pertinence of factors during the implementation of the framework.

The stages involved in implementing the framework are described below:

Stage 1: $\quad$ Selection of experts and experienced stakeholders

Stage 2: $\quad$ Listing factors that influence passengers' satisfaction 
Stage 3: $\quad$ Categorizing listed factors

Stage 4: $\quad$ Narrowing down factors

Stage 5: $\quad$ Panel-based ranking and weighing of factors

Stage 6: Development of Passengers' Satisfaction Key Indicators (PSKI)

Stage 7: Development of Passengers' Satisfactory Index (PSI)

\section{$2.1 \quad$ Selection of experts and experienced stakeholders}

In this study, the selection of qualified experts and stakeholders follows the procedure recommended by [16] and summarized in Table 1 for this study.

Table 1: Procedure to select participants for study

\begin{tabular}{|c|c|}
\hline Steps & Activities \\
\hline $\begin{array}{l}\text { Step 1: Prepare } \\
\text { Knowledge } \\
\text { Resource } \\
\text { Nomination } \\
\text { Worksheet } \\
\text { (KRNW) }\end{array}$ & $\begin{array}{l}\text { - Identify relevant disciplines or specializations: } \\
\text { - Academics } \\
\text { - Regulators } \\
\text { - Operators of ferry service } \\
\text { - Passengers/Customers } \\
\text { - Identify relevant Organizations such as Speed Boat Operators' Trade Union } \\
\text { - Identify relevant academic and Practitioners Literature }\end{array}$ \\
\hline $\begin{array}{l}\text { Populate KRNW } \\
\text { with names }\end{array}$ & $\begin{array}{l}\text { - Write names of individuals in relevant disciplines and specializations: } \\
\text { - Academics: get names from academic literatures as well as accredited Maritime related } \\
\text { departments of tertiary institutions } \\
\text { - Operators: get names from practitioners literatures as well as the list of } \\
\text { - } \quad \text { Registered operators from the Regulators } \\
\text { - Registered operators from Speed Boat Operators Trade Unions } \\
\text { - Regulators: Get names from practitioners literatures (Bulletin and Newsletter) as well as } \\
\text { - Passengers: get names of experienced and frequent travellers from the list of: } \\
\text { - Men, Women and Youth Associations in those islands only accessible by boats } \\
\text { - Government workers and other workers who reside in island communities but goes } \\
\text { - to work or offices outside their communities. } \\
\text { - Traders who purchase goods from markets located outside their island }\end{array}$ \\
\hline $\begin{array}{c}\text { Step 3: Nominate } \\
\text { Additional } \\
\text { Participants } \\
\end{array}$ & $\begin{array}{l}\text { - Contact individuals listed in the } \mathrm{KRNW} \text { and ask them to nominate others with } \\
\text { prerequisite qualifications and experience. }\end{array}$ \\
\hline $\begin{array}{l}\text { Step 4: Rank } \\
\text { Participants }\end{array}$ & $\begin{array}{l}\text { - Create four sub-lists. One for each specialization } \\
\text { - Categorize experts according to appropriate sub-list } \\
\text { - Rank participants within each list based on years of experience in ferry service industry, } \\
\text { analytical behaviour in ferry service, academic qualifications and Age. The rank and } \\
\text { weight factor of a participant can be determine using the model given by [17] thus; } \\
\text { Weight score of Expert Ei }=\text { Experience score of E } i+\text { Academic Qualification }+ \text { Age of } \\
\text { E } i+\text { Industrial Position of E } i \\
\text { Weight factor of Ei } i=E_{i}=\frac{\text { Weight score of } E_{i}}{\sum_{i=1}^{n} \text { Weight of score of } E_{i}}\end{array}$ \\
\hline $\begin{array}{l}\text { Step 5: Invite } \\
\text { Participants }\end{array}$ & $\begin{array}{l}\text { - Invite participants for each panel, with panels corresponding to each specialization } \\
\text { - } \quad \text { Invite participants in order of their ranking within their specialization sub list } \\
\text { - } \quad \text { Target size } 6 \text { - } 10 . \\
\text { - } \quad \text { Stop soliciting participants when each panel size is reached } \\
\end{array}$ \\
\hline
\end{tabular}

The objective of this stage is to identify, induce and invite at minimal time and cost the most qualified expert and stakeholders that will be committed to the study requirements. The experts and stakeholders should have no difficulty in receiving, completing and returning the questionnaire. Generally, the requirements of the study should be such that:

- time to complete the questionnaire does not exceed 30minutes and not more than 5hours to answer all the timely questionnaires for the entire period of the research study.

- the method used to send and receive the questionnaire agrees with the participants' (experts' and stakeholders) preference. Participants in the research could be asked their preferences 
and the questionnaires adapted to suit their preference. In this study emails and hardcopy media were chosen as the most appropriate media to administer the questionnaires.

- the research questions should be designed in such a way that it can readily be understood and easily responded to by the participants.

\subsection{Listing factors influencing passengers satisfaction}

In this stage, each invited participants is asked to list the relevant factors that influence passengers' satisfaction. The feedback from the participants is harmonized and consolidated into one list. The harmonization process involves standardization of factor names and phrases. For instance, size of engines was used by some participants while others use engine capacity, we standardize on engine capacity. The harmonization process also ensures no repetition of factors in the consolidated list. The consolidated list is sent to the participants for the final validation. After validation, the list, where necessary is refined. The resulting list of factors (in their categories) influencing passengers' satisfaction for this study is shown in Table 2 .

\subsection{Categorizing listed factors}

Categorical judgement has been suggested to be a veritable way to articulate practical situations. To articulate passengers' satisfaction for a ferry service, it is pertinent to categorize the influential factors listed in stage 2. Responses from participants are panel-based. Participants are treated as belonging to a panel and the opinion of each panel has equal weight. Owing to the varied background of the participants, with some panels likely to be unable, unskilled or find it boring and more demanding to embark on critical analogical reasoning to categorize factors, the researcher resorted to using the concept of analogical reasoning, structural similarity and conceptual proximity to group the factors into categories.

The categorized factors are tabulated and presented to each panel for a consensus opinion. This approach makes it easy for participants to comprehend the categorization pattern and make their input based on expert judgement. For each panel, the participants' feedback is harmonized and sent back to the respective panels for validation. In this study, three categories emanated with each category having several factors. The tabular form of the refined and validated consolidated categories generated by all the panels is shown in Table 2 .

Table 2: Consolidated categories of factors influencing Passengers' satisfaction

\begin{tabular}{|l|l|l|}
\hline \multicolumn{1}{|c|}{$\begin{array}{c}\text { Category A: Design/ } \\
\text { Operational (DO) Factors }\end{array}$} & \multicolumn{1}{|c|}{$\begin{array}{c}\text { Category B: Care, Safety \& Security } \\
\text { (CSS) Factors }\end{array}$} & \multicolumn{1}{c|}{$\begin{array}{c}\text { Category C: Environmental } \\
\text { (ENV) Factors }\end{array}$} \\
\hline Time Spent at Boarding Jetty & Attitude of Boat Operator & $\begin{array}{l}\text { Sea states: Waves, Tide, Water } \\
\text { level etc }\end{array}$ \\
\hline Cost of Transport Fare & Availability and Quality of Life Jacket & Frequency of Passing Boats \\
\hline $\begin{array}{l}\text { Speed of Boat } \\
\text { Engine and Hull Capacity and } \\
\text { Condition }\end{array}$ & Competence and Experience of Driver & $\begin{array}{l}\text { Obstructions on waterways e.g } \\
\text { presence of sebris, seaweeds, } \\
\text { shallow areas etc }\end{array}$ \\
\hline Loaded Condition of the Boat & Age of Driver & Condition \\
\hline Boat Hull Material Composition & Policies and Regulations & \\
\hline Price of Fuel & Nature and Condition of Boarding Lounge \\
\hline $\begin{array}{l}\text { Frequency } \\
\text { maintenance }\end{array}$ & Sea Pirates and Armed Robbery Activities & \\
\hline Availability of Ferry Service & $\begin{array}{l}\text { Availability and Quality of protection } \\
\text { against Storm and Sunshine }\end{array}$ & \\
\hline Flexibility of Ferry Service & Type of payload carried & \\
\hline Ceremonial Periods & Nature and Condition of Jetty & \\
\hline Number of Boats in Operation & & \\
\hline Competition amongst operators & & \\
\hline
\end{tabular}




\section{$2.4 \quad$ Narrowing down factors}

From the list of numerous factors, each category is expected to contain several factors. This stage presents a final opportunity for participants holding similar views (basically an homogeneous group of participant found in a panel) to express their view about certain factors by eliminating those factors considered unimportant to passengers' satisfaction. This stage makes use of importance ranking of factors to narrow down the number of factors in each category.

Each panel narrows down the list of factors in each of the categories. To do this, each panel is presented with a randomly listed factor in each category. Each panel will be asked to select (in no particular order) at least seven factors considered most important to passengers' satisfaction. Those factors that are repeatedly selected by more than $50 \%$ participants in the panel are chosen as the representative factors for that panel.

The feedback from the various panels is harmonized by the researchers, category by category. In this study, for each category, the lists of factors from the four panels are combined. The factors with the highest modal values are chosen as the panels' representative factors for that category. The consolidated list is sent to the panels for validation. This process will reduce the list of factors in each category to a manageable size. The consolidated and refined list of consensus factors by all the panels for this study is shown Table 3. From the Table, it can be observed that the number of factors available for ranking in each category in stage 5 does not exceed five.

\subsection{Panel-based ranking and weighing of factors}

This stage begins with each panel separately ranking the factors within each category. Each category will reflect the priority order of factors in that category for that specific panel. Based on the mean rank values, the list in a particular category can be further reduced where necessary by selecting the highly ranked factors. Factors whose mean rank values are lesser than or equal to the median value of the ranking scale of that category are considered dominant factors in that category. These factors are considered to be the dominant factors because they are crucial in determining the level of passengers satisfaction.

\subsubsection{Establishing the dominant factors and their ranks in a category}

The list of factors in each category is sent to each participant on a panel basis. The participants in each panel are asked to rank the factors in each of the categories in order of importance (rank 1 being the most important, rank 2 being the second most important, in that order). The mean rank value of a factor in a category is calculated from the rank values awarded to it by all the participants in that panel. To derive the table of ranks of all the factors in a given category from a panel, the mean rank values of the other factors in that category are caculated and tabulated. The ranks of factors in the two remaining categories are also tabulated for that panel.

A total of twelve tables will be generated from the four panels. Each of the twelve tables is valid as long as there is consensus from all the members of that panel concerning the ranks awarded to the factors in that table.

The Kendall's coefficient of concordance W will be calculated to determine the degree of consensus concerning ranks awarded to factors in each table. If the value of Kendall's coefficient is greater or equal to 0.7 , then there is consensus in the ranks awarded to the factors and the table is valid. However, where $\mathrm{W}$ is less than 0.7 , it indicates weak or no consensus and one or more of the ranks awarded to the factors in that table is not valid. In situations like this, where there is no acceptable consensus, the Likert scale elimination approach can be employed to eliminate those factors whose ranks are not generally acceptable by all members of the panel.

In the application of Likert scale approach, members of the panel are presented with the mean rank of each factor and are asked to state their opinions based on a 5-point Likert scale ranging from strongly agree to strongly disagree. They are also requested to suggest ranks for those factors they disagree with. The mean value of the opinions of all the members of the panel is determined for each factor. On the one hand, factors whose mean opinion Likert scale value is lesser than four are removed for further refinement. The suggested ranks of these factors are subjected to one or more 
rounds of Kendall's Coefficient of Concordance and Likert scale assessment until consensus is achieved within that panel. On the other hand, the mean rank values of those factors whose opinion Likert scale values are equal or greater than four are accepted.

During the iterative process, questionnaires sent to members of the panel must be properly constructed to ensure that those factors whose rank had earlier being established, maintain their ranked position at all times. Generally, the iterative rounds are carried out to determine the consensus rank of the remaining factors that were earlier eliminated for lack of consensus. A properly structured combination of Kendall's coefficient of concordance and the Likert scale assessment tools was found to reduce, if not eliminate the uncertainties surrounding the possible number of iterations required from participants to achieve consensus. Hence, this approach is an important step in the use of Delphi technique where efforts are made to reduce the time and effort spent by participants to partake in the study.

To illustrate how a structured combination of Kendall's Coefficient of Concordance and the Likert Scale assessment are applied in Delphi technique for quantitative assessment, consider on iterative process for category A factors in Table III, whose ranks are to be determined by panel 1. Each panel member is asked to rank the factors in that category. Given that the mean ranks of factors $\mathbf{a}, \mathbf{b}, \mathbf{c}, \mathbf{d}$ and $\mathbf{e}$ were found to be 1, 2, 3, 4 and 5 respectively and the value of the Kendall Coefficient W was calculated and found to be 0.4 (indicating no consensus of ranks). The mean rank of each factor in that category will be put to the Likert scale elimination test. If there is consensus rank of factors a and $\mathbf{c}$ and there was no consensus in the ranks of factors $\mathbf{b}, \mathbf{d}$ and $\mathbf{e}$. Factors $\mathbf{b}$, $\mathbf{d}$ and $\mathbf{e}$ will be eliminated while factors a and $\mathbf{c}$ will maintain their position ranks. Members of the panel will be constrained to assign importance ranks to factors $\mathbf{b}$, $\mathbf{d}$ and $\mathbf{e}$ from ranks 2, 4 and 5. The Kendall's coefficient of concordance $\mathrm{W}$ is calculated for these three factors.

$W=\frac{12\left(\sum_{i=1}^{k}\left(R_{i}-\bar{R}_{i}\right)^{2}\right)}{n^{2} K\left(K^{2}-1\right)}$

Where,

$\mathrm{W}=$ Kedall's Coefficient of Concordance

$R i=$ Mean rank of factor $i$

$n=$ Total number of opinions

$K=$ Total number of factors considered ( $\mathrm{n}=3$ in this case)

$\bar{R}_{i}=$ Mean of the sum of the mean rank of each factor considered $=\frac{R_{b}+R_{d}+R_{\varepsilon}}{3}$

Where $\mathrm{W}>0.7$, then there is consensus opinion on the ranks given to the factors. The mean rank for each factor is scrutinized. The factor with the smallest mean rank value will be ranked between a and $\mathbf{c}$ while the factors with the highest rank will be ranked last. However, where $\mathrm{W}<0.7$, implying no consensus opinion on the ranks awarded to the factors $\mathbf{b}, \mathbf{d}$ and $\mathbf{e}$, the Likert scale elimination procedure is applied again using the mean ranks of the factors. The rank positions of factors whose ranks are generally acceptable by all the panel members are accepted. Those factors without consensus rank are reiterated until consensus is achieved.

It should be noted that as factors within a category exceeds five, it becomes more complicated to place factors in their appropriate ranked position when using the structured combination of Kendall's Coefficient of Concordance and Likert scale elimination procedure in the Delphi method of qualitative assessment.

This stage of the model ends with determining the consensus rank and importance weight of each dominant factors in each category by all the panels by considering the mean rank value of each factor from all four panels. In a given category, the factor with the lowest mean value is the most important dominant factor while that with the highest mean rank value is the least dominant factor. It is possible that some factors may have equal mean rank value. 


\subsubsection{Estimating the weights of the dominant factors}

While ranking the factors primarily provides a means to finally select the dominant factors in each category, the estimation of the weights of the dominant factors gives an indication of the pertinence of these factors to their categories and by extension to the passengers' overall satisfaction.

Using the Analytical Hierarchy Processing tool which involves a pair-wise comparison of the factors in a category, the relative degree of importance (weight) of each factor can be determined. The weight of each factor can be quantified based on a total of 100points allocation to any two factors. For a category containing four dominant factors, a total of six comparisons will be made to obtain the relative weights of the factors. While for a category containing five factors, a total of ten comparisons are made. Generally, the number of comparisons are derived using the combination formula:

$$
{ }^{n} C_{r=\frac{n !}{(n-r) ! n !}} \text { where } \mathrm{n}=\text { number of factors; } \mathrm{r}=\text { pair of factors }
$$

For each panel, the structured combination of Kendall's Coefficient of Concordance and Likert scale elimination procedure are implemented to achieve consensus on the pair-wise comparison of the weights of the factors. The matrices are developed by the researchers from a panel's consensus points allocated to the factors and the various steps in AHP analysis are implemented to determine the importance weights of the dominant factors in a given category for that panel.

The overall consensus importance weight of each dominant factor in each category by all the panels can be determined by taking the mean importance weights from all four panels. The rank and importance weight of each factor for all the categories in this study are shown in Table 3.

Table 3: Rank and Weight of Narrowed Down Consolidated List of Consensus Factors

\begin{tabular}{|c|c|c|c|c|c|c|c|c|}
\hline \multicolumn{3}{|c|}{ Category A: DO Factors } & \multicolumn{3}{|c|}{ Category B: CSS Factors } & \multicolumn{3}{|c|}{ Category C: ENV Factors } \\
\hline Factor & Rank & Weight & Factor & Rank & Weight & Factor & Rank & Weight \\
\hline $\begin{array}{l}\text { a) Cost of } \\
\text { Transport } \\
\text { Fare }\end{array}$ & 1 & 0.30 & $\begin{array}{l}\text { f) Competence } \\
\text { and Experience } \\
\text { of Driver }\end{array}$ & 1 & 0.35 & $\begin{array}{l}\text { k) Sea states: Waves, } \\
\text { Tide, Water level etc }\end{array}$ & 1 & 0.33 \\
\hline $\begin{array}{l}\text { b) } \\
\text { Engine/Hull } \\
\text { Condition }\end{array}$ & 2 & 0.24 & $\begin{array}{l}\text { g) Policies and } \\
\text { Regulations }\end{array}$ & 2 & 0.27 & $\begin{array}{l}\text { l) Obstructions on } \\
\text { waterways } \\
\text { presence of } \\
\text { seaweeds, } \\
\text { areas etc }\end{array}$ & 2 & 0.31 \\
\hline $\begin{array}{l}\text { c) Speed of } \\
\text { Boat }\end{array}$ & 3 & 0.18 & $\begin{array}{l}\text { h) Availability } \\
\text { and Quality of } \\
\text { Life Jacket }\end{array}$ & 3 & 0.21 & $\begin{array}{l}\text { m) Frequency of } \\
\text { Passing Boats }\end{array}$ & 3 & 0.19 \\
\hline $\begin{array}{l}\text { d) Loaded } \\
\text { Condition of } \\
\text { the Boat }\end{array}$ & 4 & 0.17 & $\begin{array}{l}\text { i) Availability } \\
\text { and Quality of } \\
\text { protection } \\
\text { against Storm } \\
\text { and Sunshine }\end{array}$ & 4 & 0.1 & $\begin{array}{l}\text { n) Weather (Storm/ } \\
\text { Sunshine) Condition }\end{array}$ & 4 & 0.17 \\
\hline $\begin{array}{l}\text { e) Time Spent } \\
\text { at Boarding } \\
\text { Jetty }\end{array}$ & 5 & 0.11 & $\begin{array}{l}\text { j) Attitude of } \\
\text { Boat Operator }\end{array}$ & 5 & 0.07 & & & \\
\hline
\end{tabular}

\subsection{Development of Passengers' Satisfaction Key Indicators (PSKI)}

The PSKI gives a qualitative and quantitative view about the impact of a block (category) of dominant factors with structural similarities and conceptual proximity on the overall level of passengers satisfaction. The development of a PSKI involves the aggregation of the consensus ranked factors of a particular category from all the panels. The PSKI for any category $\mathrm{j}$ can be determined from the following relation:

$$
(P S K I)_{j}=\sum_{i}^{n}\left[(D F W)_{i} \times(P O V)_{i}\right]
$$

$\left[(D F W)_{i}=\right.$ Importance weight of dominant factor $i$ in category $j$ 
$(P O V)_{i}=$ Passengers' Opinion Value about factor $i$. This is a linguistic value assigned to a variable used by a passenger to express an opinion about a dominant factor $i$ which is a component of the ferry service operation.

The fuzzy PS set definition derived from a consensus opinion is shown in Fig.3. Tables 4 to 6 show the criteria used to rate the POV while Table 7 shows criteria for PS set definition.

Table 4: Criteria for Rating the Passengers' Opinion (POV description) on Boat Design/Operations

\begin{tabular}{|c|c|c|c|}
\hline \multicolumn{4}{|r|}{ Design and Operation Category Factors } \\
\hline Factors & Rank & $\begin{array}{c}\text { Passengers' } \\
\text { Opinion } \\
\end{array}$ & Description (wrt industry experience) \\
\hline $\begin{array}{c}\text { Cost of } \\
\text { Transport } \\
\text { Fare }\end{array}$ & $\begin{array}{c}1 \\
2-3 \\
4-6 \\
7-8 \\
9-10\end{array}$ & $\begin{array}{l}\text { Too High } \\
\text { High } \\
\text { Moderate } \\
\text { Low } \\
\text { Very Low }\end{array}$ & $\begin{array}{l}\text { The transport fare is excessive and too high above industry standard } \\
\text { The transport fare is slightly beyond industry standard } \\
\text { The transport fare is generally within industry standard acceptable by the passengers } \\
\text { The transport fare is slightly below industry standard } \\
\text { The transport fare is much below industry standard }\end{array}$ \\
\hline $\begin{array}{l}\text { Engine and } \\
\text { Hull } \\
\text { Condition }\end{array}$ & $\begin{array}{c}1 \\
2-3 \\
4-6 \\
7-8 \\
9-10\end{array}$ & $\begin{array}{l}\text { Very Poor } \\
\text { Poor } \\
\text { Good } \\
\text { Very Good } \\
\text { Excellent }\end{array}$ & $\begin{array}{l}\text { Boat moves slowly but consumes much fuel. Engine/hull Frequently fail during voyage } \\
\text { Boat moves slowly but consumes much fuel. Engine/Hull occasionally fail during voyage } \\
\text { Boat speed and fuel consumption are okay. Engine/Hull failure is reasonably low during } \\
\text { voyage } \\
\text { Boat speed and fuel consumption are very good. Engine/Hull failure rarely occurs during } \\
\text { voyage } \\
\text { Boat speed and fuel consumption are at design condition. Engine/Hull failure is unlikely } \\
\text { to occur }\end{array}$ \\
\hline $\begin{array}{c}\text { Speed of } \\
\text { Boat }\end{array}$ & $\begin{array}{l}1 \\
2-3 \\
4-6 \\
7-8 \\
9-10\end{array}$ & $\begin{array}{l}\text { Very Slow } \\
\text { Slow } \\
\text { Moderate } \\
\text { High } \\
\text { Very High }\end{array}$ & $\begin{array}{l}\text { The speed of the boat is below } 12 \text { Knots for routes without regulation. } 10 \% \text { of speed } \\
\text { regulation limit for routes with speed regulation. } \\
\text { The boat speed is between } 12-16 \text { Knots for routes without regulation. } 20-30 \% \text { of speed } \\
\text { regulation limit for routes with speed regulation. } \\
\text { The speed of the boat is about } 23 \text { Knots for routes without regulation. } 40-60 \% \text { of speed } \\
\text { regulation limit for routes with speed regulation. } \\
\text { The boat speed is between } 23-30 \text { Knots for routes without regulation. } 70-80 \% \text { of speed } \\
\text { regulation limit for routes with speed regulation. } \\
\text { The speed of the boat is above } 30 \text { Knots for routes without regulation. } 90-100 \% \text { of speed } \\
\text { regulation limit for routes with speed regulation. }\end{array}$ \\
\hline $\begin{array}{c}\text { Boat } \\
\text { Loaded } \\
\text { Condition }\end{array}$ & $\begin{array}{l}1-3 \\
4-7 \\
8-10\end{array}$ & $\begin{array}{l}\text { Overloaded } \\
\text { Slightly } \\
\text { Overloaded } \\
\text { or } \\
\text { Underloaded } \\
\text { Optimally } \\
\text { Loaded } \\
\end{array}$ & $\begin{array}{l}\text { Waterline is near the top edge of the boat. It depends on the cargo carrying capacity of the } \\
\text { boat } \\
\text { Waterline is slightly above or below the design waterline mark. It depends on the boat } \\
\text { hull capacity } \\
\text { Waterline is at the design waterline mark }\end{array}$ \\
\hline $\begin{array}{l}\text { Time Spent } \\
\text { at Boarding } \\
\text { Jetty }\end{array}$ & $\begin{array}{c}1 \\
2-3 \\
4-6 \\
7-8 \\
9-10\end{array}$ & $\begin{array}{l}\text { Too Much } \\
\text { A Lot } \\
\text { Reasonable } \\
\text { Little } \\
\text { Very Little }\end{array}$ & $\begin{array}{l}\text { Passengers spent too much time waiting to board the boat } \\
\text { Passengers spent a lot of time waiting to board the boat } \\
\text { Passengers spent a some (reasonable) time waiting to board the boat } \\
\text { Passengers spent little time waiting to board the boat } \\
\text { Passengers board the boat as soon as they arrive the boarding lounge }\end{array}$ \\
\hline
\end{tabular}


Table 5: Criteria for Rating the Passengers' Opinion (POV description) on Care, Safety and Security

\begin{tabular}{|c|c|c|c|}
\hline \multicolumn{4}{|r|}{ Care Safety and Security Category Factors } \\
\hline Factors & Rank & $\begin{array}{c}\text { Passengers' } \\
\text { Opinion }\end{array}$ & Description (wrt industry experience) \\
\hline $\begin{array}{l}\text { Competence } \\
\text { and Experience } \\
\text { of Driver }\end{array}$ & $\begin{array}{c}1 \\
2-3 \\
4-6 \\
7-8 \\
9-10\end{array}$ & $\begin{array}{l}\text { Very Low } \\
\text { Low } \\
\text { Moderate } \\
\text { High } \\
\text { Very High }\end{array}$ & $\begin{array}{l}\text { The Driver is a trainee or has no experience about the route or boat driving } \\
\text { The Driver is recently trained or has very little experience about the route or boat driving } \\
\text { The Driver has <2years of experience about the route or boat driving and built some } \\
\text { competence } \\
\text { The Driver is competent and has several years of experience about the route } \\
\text { The Driver has distinctive competence in driving and has many years of experience } \\
\text { about the route }\end{array}$ \\
\hline $\begin{array}{l}\text { Policies and } \\
\text { Regulations }\end{array}$ & $\begin{array}{c}1 \\
2-3 \\
4-6 \\
7-8 \\
9-10\end{array}$ & $\begin{array}{l}\text { Very Bad } \\
\text { Bad } \\
\text { Moderate } \\
\text { Good } \\
\text { Very Good }\end{array}$ & $\begin{array}{l}\text { Passengers view policies and regulations as highly against their interest } \\
\text { Passengers view policies and regulations as unfavourable to them } \\
\text { Passengers view policies and regulations as fair and for the good of the industry } \\
\text { Passengers view policies and regulations as favourable to them } \\
\text { Passengers view policies and regulations as very favourable to them }\end{array}$ \\
\hline $\begin{array}{l}\text { Availability/ } \\
\text { Quality of Life } \\
\text { Jacket }\end{array}$ & $\begin{array}{c}1 \\
2-3 \\
4-7 \\
8-10\end{array}$ & $\begin{array}{l}\text { Very Poor } \\
\text { Poor } \\
\text { Moderate } \\
\text { High }\end{array}$ & $\begin{array}{l}\text { No life jacket are provided to passengers } \\
\text { Damaged and outdated Life Jackets are provided to some or all the Passengers } \\
\text { Good quality Life jackets are provided to some or all the passengers } \\
\text { Very good quality life jackets are provided to all passengers }\end{array}$ \\
\hline $\begin{array}{l}\text { Availability and } \\
\text { Quality of } \\
\text { Protection } \\
\text { against Weather }\end{array}$ & $\begin{array}{c}1 \\
2-3 \\
4-7 \\
8-10\end{array}$ & $\begin{array}{l}\text { Very Poor } \\
\text { Poor } \\
\text { Moderate } \\
\text { High }\end{array}$ & $\begin{array}{l}\text { No protection against harsh weather } \\
\text { Tarpaulin is used to cover passengers when such harsh weather condition arises } \\
\text { Boat has in-built roof but no side protection against harsh prevailing weather condition } \\
\text { Boat has in-built roof and side protection against harsh prevailing weather }\end{array}$ \\
\hline $\begin{array}{l}\text { Attitude of } \\
\text { Boat Operator }\end{array}$ & $\begin{array}{c}1 \\
2-3 \\
4-6 \\
7-8 \\
9-10\end{array}$ & $\begin{array}{l}\text { Very poor } \\
\text { Poor } \\
\text { Moderate } \\
\text { Good } \\
\text { Very Good }\end{array}$ & $\begin{array}{l}\text { Operator is very rude and non challant to passengers' complaints. } \\
\text { Operator is not friendly and care less about passengers' complaints. } \\
\text { Operator is reasonably friendly and sometimes listens to passengers' complaints. } \\
\text { Operator is friendly, listens to passengers complaints but makes little effort to solve them } \\
\text { Operator is very friendly, listens to passengers' complaints and makes practical effort to } \\
\text { help out }\end{array}$ \\
\hline
\end{tabular}

Table 6: Criteria for Rating the Passengers' Opinion (POV description) on Environmental Factors

\begin{tabular}{|c|c|c|c|}
\hline \multicolumn{4}{|r|}{ Environmental Category Factors } \\
\hline Factors & Rank & $\begin{array}{c}\text { Passengers' } \\
\text { Opinion }\end{array}$ & Description (wrt industry experience) \\
\hline $\begin{array}{l}\text { Sea states: } \\
\text { Waves, } \\
\text { Tide, Water } \\
\text { level etc }\end{array}$ & $\begin{array}{c}1 \\
2-3 \\
4-6 \\
7-8 \\
9-10\end{array}$ & $\begin{array}{l}\text { Extreme } \\
\text { Rough } \\
\text { Moderate } \\
\text { Mild } \\
\text { Calm }\end{array}$ & $\begin{array}{l}\text { Waves, Tide and Water levels are at the maximum levels } \\
\text { Waves, Tide and Water levels are quite high } \\
\text { Waves, Tide and Water levels are at moderate level } \\
\text { Waves, Tide and Water levels are at low level } \\
\text { There are no waves. }\end{array}$ \\
\hline $\begin{array}{c}\text { Obstruc- } \\
\text { tions on } \\
\text { waterways }\end{array}$ & $\begin{array}{c}1 \\
2-3 \\
4-6 \\
7-8 \\
9-10\end{array}$ & $\begin{array}{l}\text { Very High } \\
\text { High } \\
\text { Moderate } \\
\text { Low } \\
\text { Very Low } \\
\end{array}$ & $\begin{array}{l}\text { The waterway is extremely infested with debris and seaweeds } \\
\text { The waterway is highly infested with debris and seaweeds } \\
\text { The waterway is moderately infested with debris and seaweeds } \\
\text { The waterway is minimally infested with debris and seaweeds } \\
\text { The waterway has little or no obstructions by debris and seaweeds }\end{array}$ \\
\hline $\begin{array}{c}\text { Frequency } \\
\text { of Passing } \\
\text { Boats }\end{array}$ & $\begin{array}{r}1 \\
2-3 \\
4-6 \\
7-8 \\
9-10\end{array}$ & $\begin{array}{l}\text { Highly } \\
\text { Frequent } \\
\text { Frequent } \\
\text { Average } \\
\text { Low } \\
\text { Very Low }\end{array}$ & $\begin{array}{l}\text { The waterway is highly congested with passing boats } \\
\text { The waterway is quite busy with a good number of boats moving pass each other. } \\
\text { The waterway is moderately congested. The boat by-passes reasonable number of other } \\
\text { boats } \\
\text { The boat occasionally by-passes very few other boats during a voyage } \\
\text { The boat rarely by-passes any other boat during a voyage }\end{array}$ \\
\hline $\begin{array}{l}\text { Weather } \\
\text { (Storm/ } \\
\text { Sunshine) } \\
\text { Condition }\end{array}$ & $\begin{array}{c}1 \\
2-3 \\
4-6 \\
7-8 \\
9-10\end{array}$ & $\begin{array}{l}\text { Extreme } \\
\text { Harsh } \\
\text { Moderate } \\
\text { Mild } \\
\text { Ambient }\end{array}$ & $\begin{array}{l}\text { Frequent Long duration and high intensity of rainfall and/or sunshine } \\
\text { Frequent mean duration and high intensity of rainfall and/or sunshine } \\
\text { Moderate number of occurrences of short duration and mean intensity of rainfall and/or } \\
\text { sunshine } \\
\text { Less Frequent mean or short duration and mean intensity of rainfall and/or sunshine } \\
\text { Passengers experience little or no rainfall and/or scorching sun }\end{array}$ \\
\hline
\end{tabular}


Table 7: Passengers' Satisfaction for all categories of dominant factors

\begin{tabular}{|c|l|l|}
\hline Rank & \multicolumn{1}{|c|}{ Passengers Satisfaction Variable } & \multicolumn{1}{c|}{ Description } \\
\hline 1 & Very Dissatisfactory & Passengers expectations are not met \\
\hline $2-3$ & Dissatisfactory & Satisfies few of the Passengers expectation \\
\hline $4-6$ & Moderately Satisfactory & Satisfies some of the Passengers expectation \\
\hline $7-8$ & Satisfactory & Satisfies most of the Passengers expectation \\
\hline $9-10$ & Very Satisfactory & Satisfies all the Passengers expectation \\
\hline
\end{tabular}

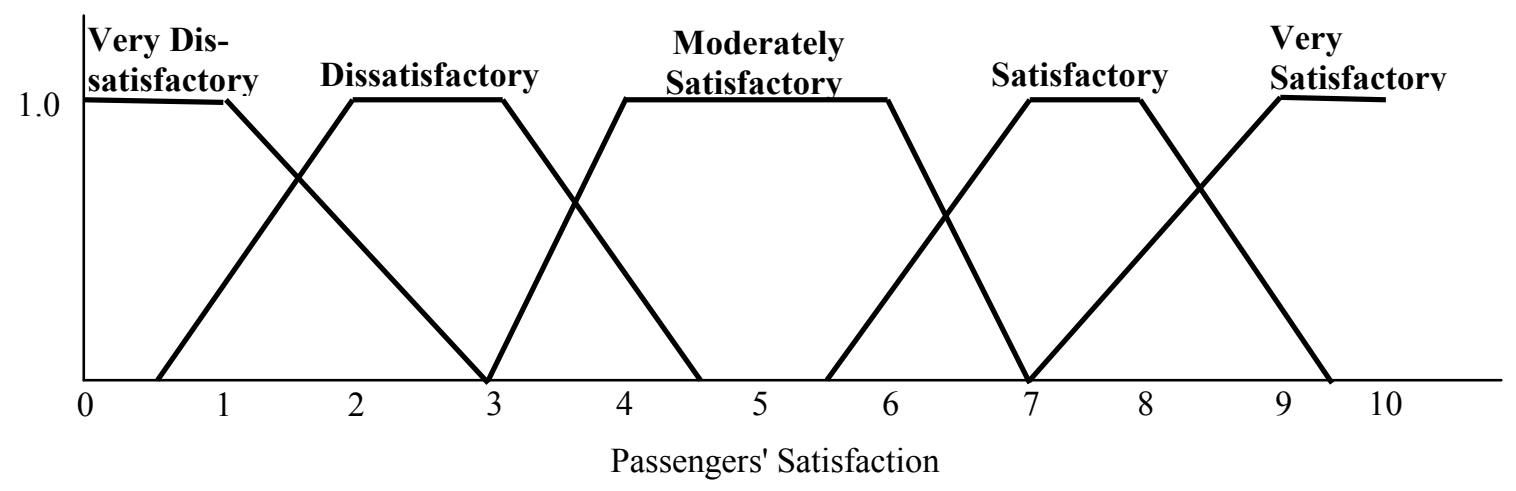

Fig.3: Fuzzy PS set definitions

In this study, three PSKI were generated and they include;

Design/Operations-PSKI generated from Category A

Care/Safety/Security-PSKI generated from Category B

Environment-PSKI generated from Category $\mathrm{C}$

\subsection{Development of Passengers' Satisfactory Index (PSI)}

The Passengers' Satisfactory Index (PSI) indicates the overall passengers' satisfactory level for a given ferry service. It is an aggregation of all the PSKIs (from all the categories) with the importance weights of each category. The PSI for a ferry service can be determined from the following relation:

$$
P S I=\sum_{i}^{n}\left[(P S K I)_{i} \times(I w)_{i}\right]
$$

Where,

$n$ is the number of categories

$(\mathrm{PSKI})_{i}$ is the value of Passengers' Satisfaction Key Indicator for category $i$

$(I w) i$ is the importance weight of category $i$ to the overall Passengers' satisfaction.

The (Iw) $i$ of a category $i$ of factors can be determined by using the same AHP analysis based procedure earlier used to determine the importance weight of the dominant factors. However, since there are just three categories to be compared, a total of three pair-wise comparisons will be made to obtain the relative weights of the categories. The mean of the four importance weights derived from the four panel for a category gives the consensus importance weight or contribution of that category to the overall Passengers' satisfactory level. The importance weights of the three categories derived from all the panels in this study are shown in Table 8.

Table 8: Weight of Category

\begin{tabular}{|l|c|}
\hline Category & Weight \\
\hline DO Related Category & 0.4 \\
\hline CSS Related Category & $\mathbf{0 . 4}$ \\
\hline ENV Related Category & $\mathbf{0 . 2}$ \\
\hline
\end{tabular}




\subsection{Test Case}

The PSKIs and PSI is to be determined for a service rendered during the Easter period by an operator of Almarine's Passport 19 speed boat, who carried 19 passengers from Warri to Forcados terminal. It was observed that the passengers paid a very high transport fare and spent little time at the boarding lounge to board an open boat with no protection against weather and was slightly overloaded with payload. The boat whose hull and engine conditions are good was driven through the busy and mild waterways at moderate speed during the harsh sunny season by a reasonably friendly boat driver with less than two years driving experience who provided passengers with some good quality life jacket without the supervision of regulators whose policies are deemed unfavourable to passengers welfare and whose inaction has not helped to clean up the highly debris infested waterways.

The PSKIs and PSI for this ferry service conditions is determined thus:

The values of the passengers' opinion about each factor are first determined from the fuzzy POV set definitions in Tables 4, 5 and 6 and the importance weight of each dominant factor (DFW) is got from Table 3.

\section{Determine DO-PSKI for Design and Operations related Category}

The POV of the dominant factors a, b, c, d and e are respectively: 2, 6, 5, 1 and 7

The DFW for the dominant factors a, b, c, $\mathrm{d}$ and e are respectively $0.30,0.24,0.18,0.17$ and 0.11

The DO-PSKI $=(2 \times 0.30)+(6 \times 0.24)+(5 \times 0.18)+(1 \times 0.17)+(7 \times 0.11)=3.88$

A DO-PSKI value of 3.88 on the Fuzzy PS set definitions shown in Fig.3 is in the range of Dissatisfactory and Moderately Satisfactory.

Determine CSS-PSKI for Passengers Care, Safety and Security related Category

The POV of dominant factors $\mathrm{f}, \mathrm{g}, \mathrm{h}, \mathrm{i}$ and $\mathrm{j}$ are respectively: 4, 3, 5, 1 and 4

The DFW for the dominant factors $\mathrm{E}, \mathrm{F}, \mathrm{G}$ and $\mathrm{H}$ are respectively $0.35,0.27,0.21,0.1$ and 0.07

The CSS-PSKI $=(4 \times 0.35)+(3 \times 0.27)+(5 \times 0.21)+(1 \times 0.1)+(4 \times 0.07)=3.64$

A CSS-PSKI value of 3.64 on the Fuzzy PS set definitions shown in Fig.3 is in the range of Dissatisfactory and Moderately Satisfactory

\section{Determine Env-PSKI for Environment related Category}

The POV of dominant factors $\mathrm{k}, 1, \mathrm{~m}$ and $\mathrm{n}$ are respectively: $8,2,3$ and 2

The DFW for the dominant factors $\mathrm{k}, 1,1, \mathrm{~m}$ and $\mathrm{n}$ are respectively $0.33,0.31,0.19$ and 0.17

The Env-PSKI $=(8 \times 0.33)+(2 \times 0.31)+(3 \times 0.19)+(2 \times 0.17)=4.17$

An Env-PSKI value of 4.17 on the Fuzzy PS set definitions shown in Fig. 3 is in the range of Moderately Satisfactory

Determine the PSI of the Ferry Service

The DO-PSKI, CSS-PSKI and Env-PSKI are respectively: 3.88, 3.64 and 4.17

The importance weight of each PSKI category are shown in Table 8

The PSI can be determined using the following relation:

$\mathrm{PSI}=(3.88 \times 0.4)+(3.64 \times 0.4)+(4.17 \times 0.2)=3.84$

A PSI value of 3.84 on the Fuzzy PS set definitions shown in Fig.3 reveals that the ferry service is in the range of Dissatisfactory and Moderately Satisfactory. The result gives a generally acceptable and realistic view about the level of passengers' satisfaction for the given ferry service offered. The PSI value determined corresponded with the general opinion of the passengers about the service offered by this boat operator in the Warri-Forcados Ferry Route. However, passengers continue to patronize this operator because there are no alternative transport means to and from their destination. 


\subsection{Conclusions}

The framework developed proved that the Delphi survey technique when properly combined with qualitative assessment tools provides a very powerful and reliable method to holistically evaluate passengers' sentiments to ferry service operations. The reliability of the framework is anchored on the rigorous steps employed in sourcing for participants in the survey, soliciting and categorizing expert opinions as well as the reliable analytical techniques used to evaluate and grade individual and consensus opinions from the panels of experienced stakeholders in the ferry service industry. However, it should be noted that as the number of dominant factors influencing passengers' satisfaction increases beyond five in each category, the framework becomes more difficult to implement. The implementation of the framework using the test case, yielded a PSI value of 3.84 whose linguistic meaning agrees with the popular opinion that the ferry service offered by that boat operator does not satisfy most of the passengers' expectations.

\section{References}

[1] J.V. Nickerson et al., Matching Mechanisms to situations through the wisdom of the crowd, in Proceedings of the 13th International Conference on Information Systems, Phoenix, 2009

[2] K.J. Schmucker, Fuzzy sets, natural language computations and risk analysis, Computer Science Press, Rockville, MD, 1984.

[3] L.B. Smith et al., Object name learning provides on-the-Job training for attention, Psychological Science. 13(1) (2002) 13-19.

[4] G. Lupyan, D.H. Rakison, J.L. McClelland, Language is not just for talking: redundant labels facilitate learning of novel categories, Psychological Science. 18(12) (2007) 1077-1083.

[5] B. Tversky et al., Talking about events, in E. Pederson, J. Bohnemeyer, R. Tomlin (Editors), Event representation in language and cognition, Cambridge: Cambridge University Press, 2010, pp. 216-227.

[6] B. Tversky, Visualizing thought. Topics in Cognitive Science.3(3) (2011) 499-535.

[7] D. Gentner, and A.B. Markman, Defining structural similarity, Journal of Cognitive Science. 6 (2006) 1-20.

[8] K.J. Holyoak, P. Thagard, Analogical mapping by constraint satisfaction, in cognitive modeling, Polk, T.A. and Seifert, C.M. (Eds.), MIT Press, Cambridge, MA, 2002, pp. 849-909.

[9] M.L. Gick, K.J. Holyoak, Analogical problem solving, Cognitive Psychology. 12(3) (1980) 306-355.

[10] M.L. Gick, K.J. Holyoak, Schema induction and analogical transfer, Cognitive Psychology. 15(1) (1983) 1-39.

[11]F. Harary, Graph theory, Addison Wesley, Reading, MA, 1994.

[12] J.V. Nickerson et al., The spatial nature of thought: Understanding information systems design through diagrams, in Proceedings of the 29th International Conference on Information Systems, Boland, R., Limayem, M., and Pentland B. (Eds.), Paris, France, 2008.

[13] Y.F. Hu, Efficient, High-quality force-directed graph drawing, The Mathematica Journal. 10(1) (2006) 37-71.

[14] R.C. Schmidt, Managing Delphi surveys using nonparametric statistical techniques, Decision Sciences. 28(3) (1997) 763-774.

[15]F. Hasson, S. Keeney, H. McKenna, Research guidelines for the Delphi survey technique, Journal of Advanced Nursing. 32(4) (2000) 1008-1015.

[16] A.L. Delbecq, A.H.Van de Ven, D.H. Gustafson, Group techniques for program planning: A guide to nominal group and Delphi processes, Scott, Foresman and Company, GlEnview, Illinois, 1975.

[17]D. Yuhua, Y. Datao, Estimation of failure probability of oil and gas transmission pipelines by fuzzy fault tree analysis, J loss Prevent Proc. 18 (2005) 83-88. 